\title{
Antimycotic and Antibacterial Activity of Aframomum melegueta Seed Extracts Against Bacteria and Fungi Species from Food Sources
}

\author{
Alloysius Chibuike Ogodo ${ }^{1,}$, Chioma Blessing Nwaneri², Dawn Ify Agwaranze', \\ Jonathan Ewanfo Inetianbor ${ }^{1}$, Christopher Uchechukwu Okoronkwo ${ }^{3}$ \\ ${ }^{1}$ Department of Microbiology, Faculty of Pure and Applied Sciences, Federal University Wukari, Wukari, Nigeria \\ ${ }^{2}$ Department of Microbiology, School of Biological Sciences, Federal University of Technology Owerri, Owerri, Nigeria \\ ${ }^{3}$ Department of Microbiology, Faculty of Biological and Physical Sciences, Abia State University Uturu, Uturu, Nigeria
}

Email address:

ogodoac@fuwukari.edu.ng (A. C. Ogodo)

*Corresponding author

\section{To cite this article:}

Alloysius Chibuike Ogodo, Chioma Blessing Nwaneri, Dawn Ify Agwaranze, Jonathan Ewanfo Inetianbor, Christopher Uchechukwu Okoronkwo. Antimycotic and Antibacterial Activity of Aframomum melegueta Seed Extracts Against Bacteria and Fungi Species from Food Sources. Central African Journal of Public Health. Vol. 3, No. 4, 2017, pp. 44-50. doi: 10.11648/j.cajph.20170304.12

Received: June 15, 2017; Accepted: July 21, 2017; Published: August 16, 2017

\begin{abstract}
The antibacterial and antimycotic activity of Aframomum melegueta seeds were investigated against Escherichia coli, Staphylococcus aureus, Pseudomonas earuginosa, Salmonella species, Klebsiella species, Bacillus species, Fusarium species, Rhizopus species, Aspergillus species, Penicillium species and Mucor species isolated from spoiled bread and tomatoes using agar well diffusion method. The result showed that the ethanol extract exhibited higher antibacterial activity more than the aqueous extract with Bacillus sp. having the highest zone of inhibition (28mm, 23mm), followed by Salmonella sp. $(26 \mathrm{~mm}, 22 \mathrm{~mm}), S$. aureus $(24 \mathrm{~mm}, 19 \mathrm{~mm})$, Klesiella $\mathrm{sp} .(22 \mathrm{~mm}, 17 \mathrm{~mm})$ and E. coli $(20 \mathrm{~mm}, 16 \mathrm{~mm})$ while P. earuginosa was the least $(18 \mathrm{~mm}, 15 \mathrm{~mm})$. The antifungal activity showed that Rhizopus sp. was the most inhibited by both ethanol and aqueous extracts respectively (20mm and $16 \mathrm{~mm})$, followed Penicillium sp. (17mm and 12mm), Aspergillus sp. (14mm and $11 \mathrm{~mm}$ ) and Fusarium sp. (14mm and $10 \mathrm{~mm})$ while Mucor sp. was the least $(15 \mathrm{~mm}$ and $9 \mathrm{~mm})$. The minimum inhibitory concentrations (MICs) of the aqueous seed extracts showed that MIC of E. coli, S. aureus, Salmonella sp. and Bacillus sp. was 20mg/mL. MIC for P. earuginosa, Klesiella sp. and Rhizopus sp. was $30 \mathrm{mg} / \mathrm{mL}$ while Fusarium sp., Aspergillus sp., Penicillium sp. and Mucor sp. have MICs of $50 \mathrm{mg} / \mathrm{mL}$. The MICs of the ethanolic extract showed that E. coli and $S$. aureus have MICs of $10 \mathrm{mg} / \mathrm{mL}$, P. earuginosa, Klesiella sp., Penicillium sp. and Rhizopus sp. have 20mg/mL, Fusarium sp., Aspergillus sp. and Mucor sp. have 30mg/mL while Bacillus sp. was the most susceptible with MIC of $5 \mathrm{mg} / \mathrm{mL}$. The low MICs are indication of strong antibacterial and antimycotic effects of the extracts. Hence, the extracts could be used in treating infections associated with the test organisms and as well as serve as potential food preservative.
\end{abstract}

Keywords: Antifungal Activity, Antibacterial Activity, Food Preservation, Foodborne Pathogens, Aframomum melegueta Extracts

\section{Introduction}

The use of plants as food, spices, vegetables and in the treatment of common infectious diseases have been practiced since antiquity, even before the discovery of microorganisms by humans [1-3]. A number of plants have been found to possess antimicrobial properties and are employed in traditional medicine [4]. The medicinal value of these plants have been attributed to some phytochemical constituents of the plants including alkaloids, flavonoids, tannins and phenolic compounds which are toxic to microorganisms [3, 5].

Aframomum melegueta known as alligator pepper belongs to the family zingiberaceae with ginger. It is tropical herbaceous perennial plant of the genus Aframomum. It is widely spread across tropical Africa including Nigeria, Liberia, Sierra Leone, Ghana, Cameroon, Cote D' ivoire and 
Togo. The seeds have pungent peppery taste due to aromatic ketones and have been reported to have both medicinal and nutritive values [3, 6-7]. The seeds have been reported to contain the phytoconstituents, gingerol, methyl-6-gingero, shogaol and paradol that contribute to its antimicrobial properties [8]. According to the report of [9], extracts of Aframomum melegueta can be used in the treatment and prevention of wound infections owing to its antiseptic and bactericidal properties. Extracts of Aframomum melegueta have been found to inhibit the growth of Bacillus cereus, Staphylococcus aureus, Escherichia coli, Salmonella typhi and klebsiella pneumonia [10]. [11] reported that extracts Aframomum melegueta was effective against Aspergillus flavus, Fusarium oxystosporun, Rhizopus stoloniger, Botryodiplodis theobromae and Penicillium crysogenum isolated from rotten yam. Also, the research of [12] stated that Aframomum melegueta extracts was found to be effective against E. coli, Candida albicans, S. aureus, P. aeruginosa, Salmonella sp., Streptococcus sp. and Neisseria gonorrhea.

Microorganisms present in food can lead to their spoilage and as well cause food poisoning to humans leading to infection or intoxication [13]. Escherichia coli (EHEC), haemorrhagic diarrhoea, which occasionally can lead to kidney failure and death. Salmonella and causes salmonellosis mainly from foods of animal origin. Staphylococcus aureus and Bacillus cereus cause staphylococcal and Bacillus foodborne intoxication due to their ability to form heat stable toxins [14-16]. Aspergillus niger causes aspergillosis in immunocompromised individuals and has been implicated in otomycosis in healthy persons as well as allergic reactions such as asthma and pneumonitis as well as toxin production in food [7, 17]. Mucor species are found in the soil, digestive system, decayed fruits, vegetables and old bread and may cause infection in man, frogs, amphibian cattle and swine [18]. Fusarium and Penicilium species can cause diseases in plants and animals [19]. Hence, the present research investigated the antibacterial and antifungal activity of Aframomum melegueta seed extracts against Escherichia coli, Staphylococcus aureus, Pseudomonas earuginosa, Salmonella species, Klesiella species, Bacillus species, Fusarium species, Rhizopus species, Aspergillus species, Penicillium species and Mucor species isolated from spoiled tomatoes and bread.

\section{Materials and Methods}

\subsection{Collection and Preparation of Aframomum Melegueta Seeds}

Intact mature Aframomum melegueta (alligator pepper) pods were purchased from a local market in South-Eastern part of Nigeria and identified as Aframomum melegueta pods. This plant part was chosen because it is widely used in all as spice, condiments and in soup preparation as well as taken raw in most part of the country. The Aframomum melegueta pods were opened and the seeds removed and separated from the material in the pod and washed with clean sterile distilled water. The seeds were then dried using hot air oven at $40^{\circ} \mathrm{C}$ for $72 \mathrm{~h}$. The dried seeds were ground to a fine powder using a laboratory blender disinfected with $70 \%$ ethanol. The powdered sample was kept in an air tight container and stored at room temperature for further use.

\subsection{Preparation of Aqueous and Ethanol Extracts of Aframomum Melegueta Seeds}

The aqueous (water) and ethanol extracts of the sample were carried out using soaking method following a modification of the method of [20]. Exactly $200 \mathrm{~g}$ of the powdered Aframomum melegueta seed was dissolved in $500 \mathrm{~mL}$ hot sterile distilled water and $500 \mathrm{~mL} 70 \%$ ethanol respectively and allowed for $24 \mathrm{~h}$ at room temperature. The extracts were then filtered using Whatman no. 1 filter paper. The filtrates were evaporated to dryness on a water bother at $50^{\circ} \mathrm{C}$ to give the crude extract. The extracts efficiency was quantified by determining weight of the respective extracts [21]. The Aframomum melegueta extracts were stored in a desiccator until required for antibacterial and antimycotic analysis. The extracts were dissolved in appropriate volume of respective solvents to the desired concentration.

\subsection{Sterility of the Extracts}

The sterility of the extracts was determined according to the method of [22]. The respective extracts were inoculated on fresh sterile nutrient agar and incubated at $37^{\circ} \mathrm{C}$ for $24 \mathrm{~h}$. The absence of growth after incubation is an indication of sterility.

\subsection{Isolation and Maintenance of Bacterial Isolates}

The bacteria, Escherichia coli, Staphylococcus aureus, Pseudomonas earuginosa, Salmonella species, Klesiella species and Bacillus species and the fungi, Fusarium species, Rhizopus species, Aspergillus species, Penicillium species and Mucor species were isolated from spoiled tomatoes and bread following a modification of the method of [23]. Fresh tomatoes and bread were purchased from the sellers and exposed in the laboratory bench for 7 days to be deteriorated. A sterile swab was used to take samples from the deteriorated parts of the tomatoes and bread. This was used to aseptically inoculate sterile freshly prepared nutrient agar, MacConkey agar, blood agar and tomato juice agar respectively. The inoculated media were incubated for $24 \mathrm{~h}$ at $37^{\circ} \mathrm{C}$. The fungi media were incubated at room temperature for 7 days. Subsequent cultures were made on fresh medium for purity. The pure cultures of bacteria were characterized according to the method of [24]. Identification was done with reference to Bergy's manual of determinative bacteriology [25]. The fungi were identified on the basis of their cultural characteristics, microscopy and with reference to the methods described by [26]. The isolates were maintained in agar slants and stored in the refrigerator at $4^{\circ} \mathrm{C}$. 


\subsection{Standardization of the Test Isolates}

The test organisms were standardized following a slight modification of the method of [27]. Exactly $0.2 \mathrm{~mL}$ of $18 \mathrm{~h}$ broth culture of each of the test isolates was dispensed into $20 \mathrm{~mL}$ of sterile fresh nutrient broth and incubated for $4 \mathrm{~h}$ to obtain 0.5 McFarland standard. The standardization of fungi was done as described by [7]. Colonies of the subculture were transferred into $5 \mathrm{~mL}$ of sterile distilled water and adjusted, comparing with McFarland's 0.5 standard.

\subsection{Antibacterial and Antifungal Testing}

The antibacterial and antifungal activity of the crude extracts of Aframoтum melegueta were determined using agar well diffusion method described by [21] and [7] respectively with slight modifications. Exactly $0.1 \mathrm{~mL}$ and $0.2 \mathrm{~mL}$ each of the standard bacterial and fungi species were mixed in molten Mueller Hinton Agar and Sabouraud's dextrose agar (fortified with $0.05 \mathrm{mg} / \mathrm{ml}$ of chloramphenicol) respectively and poured in sterile Petri dishes. These were allowed to gel. A cork borer of $6 \mathrm{~mm}$ diameter was used to bore wells in the solidified medium and filled with extracts of $45 \mu \mathrm{l}$ of the crude extracts. Water was used as negative control. The plates were incubated at $37^{\circ} \mathrm{C}$ for $24 \mathrm{~h}$ for bacteria and at room temperature for $48 \mathrm{~h}$ for the fungi. The diameter of the zones of inhibition was measured in millimeter. Values were recorded as mean of triplicate determination.

\subsection{Determination of Minimum Inhibitory Concentrations (MICs)}

The minimum inhibitory concentrations (MICs) of the extracts were carried out according to the method of [28] with slight modification. Concentrations of $150 \mathrm{mg} / \mathrm{mL}$, $100 \mathrm{mg} / \mathrm{mL}, 50 \mathrm{mg} / \mathrm{mL}, 30 \mathrm{mg} / \mathrm{mL}, 20 \mathrm{mg} / \mathrm{mL}, 10 \mathrm{mg} / \mathrm{mL}$ and $5 \mathrm{mg} / \mathrm{mL}$ of the aqueous and ethanol extracts of the seeds of Aframomum melegueta were prepared and assayed using agar well diffusion method. The minimum inhibitory concentration was considered as the concentration of the extracts below where there was no inhibition.

\section{Results and Discussion}

\subsection{Isolation of Bacteria and Fungi Species}

Table 1. Presence of microorganism in the various spoiled food samples.

\begin{tabular}{lll}
\hline \multirow{2}{*}{ Organisms } & \multicolumn{2}{l}{ Spoiled Food Samples } \\
\cline { 2 - 3 } & Tomatoes & Bread \\
\hline Escherichia coli & + & + \\
Staphylococcus aureus & - & + \\
Pseudomonas aeruginosa & + & - \\
Salmonella species & + & + \\
Klebsiella species & + & - \\
Bacillus species & + & + \\
Fusarium species & + & + \\
Rhizopus species & + & + \\
Aspergillus species & + & + \\
Penicillium species & + & + \\
Mucor species & - & + \\
\hline & &
\end{tabular}

The isolation of microorganisms from the spoiled food items showed that Escherichia coli, Salmonella species, Bacillus species, Fusarium species, Rhizopus species, Aspergillus species and Penicillium species were present in both tomatoes and bread; Staphylococcus aureus and Mucor species were only present in bread while Pseudomonas earuginosa, and Klesiella species were present in tomatoes only (Table 1).

The bacteria and fungi isolated from the spoiled bread and tomatoes in the present study have been reported to be associated with the spoilage of the food items be previous researchers. For instance, [29] reported Candida tropicalis, Penicillium notatum, Aspergillus niger, Fusarium oxysporum, Absidia corynbifera, Rhizopus stonolifer, Escherichia coli, Klebsiella spp., Salmonella spp. and Pseudomonas aeruginosa as microbial agents of spoilage of tomato in Onitsha. Also, [30] isolated Pseudomonas, Penicillium and Rhizopus species from tomato. Rhizopus, Aspergillus, Penicillium and Mucor species have been reported to be associated with the spoilage of bread [31-32].

\subsection{Antibacterial and Antifungal Activity}

Figure 1 presented the antibacterial activity of the aqueous and ethanol extracts of Aframomum melegueta seed. The result showed that the ethanol extract exhibited higher antibacterial activity more than the aqueous extract with Bacillus sp. having the highest zone of inhibition $(28 \mathrm{~mm}$, $23 \mathrm{~mm}$ ), followed by Salmonella sp. (26mm, 22mm), $S$. aureus $(24 \mathrm{~mm}, 19 \mathrm{~mm})$, Klesiella $\mathrm{sp} .(22 \mathrm{~mm}, 17 \mathrm{~mm})$ and $E$. coli $(20 \mathrm{~mm}, 16 \mathrm{~mm})$ while $P$. aruginosa was the least $(18 \mathrm{~mm}$, $15 \mathrm{~mm})$.

The antifungal activity of the extracts of Aframomum melegueta was presented in Figure 2. The result showed that Rhizopus sp. was the most inhibited by both ethanol and aqueous extracts $(20 \mathrm{~mm}$ and $16 \mathrm{~mm})$, followed Penicillium sp. (17mm and $12 \mathrm{~mm})$, Aspergillus sp. (14mm and $11 \mathrm{~mm})$ and Fusarium sp. (14mm and $10 \mathrm{~mm})$ while Mucor sp. was the least ( $15 \mathrm{~mm}$ and $9 \mathrm{~mm})$.

In the present study, the seed extracts of Aframomum melegueta inhibited the growth of all the bacteria and fungi tested. This observation is in agreement with the report of [3] who reported effectiveness of the extract against tested organisms and suggest that the plant have broad spectrum activity. Similar observations have been reported by [33] and [10]. This antimicrobial effect could be attributed to the phytochemical constituents of the plant seed such as flavonoids, phenolic compound tannins, saponin, terpernoids, cardiac glycosides and alkaloids [3]. The present result showed that aqueous and ethanolic extracts of Aframomum melegueta were effective against Escherichia coli, Staphylococcus aureus, Pseudomonas earuginosa, Salmonella species, Klesiella species, Bacillus species, Fusarium species, Rhizopus species, Aspergillus species, Penicillium species and Mucor species. However, the ethanol extract was more effective against the test organisms than the aqueous extract. This observation is consistent with the report of other researchers; [20] in their study showed that 
ethanol extracts of Aframomum melegueta seed inhibited Escherichia coli and Salmonella typhi. [34] reported that ethanolic seed extracts Aframomum melegueta was more effective against Staphylococcus aureus, Pseudomonas aeruginosa, Proteus sp., Salmonella sp., Bacillus sp., Escherichia coli, Klebsiella sp., Aspergillus sp., Saccharomyces sp. and Candida sp. Also, [7] reported that methanol extract of Aframomum melegueta inhibited Aspergillus niger, Candida albicans and Trichophyton rubrum. These reports show that ethanol is a better solvent for the extraction of active substance from the test plant part.
It also shows that the seed extracts of Aframomum melegueta can be used in the treatment of infections associated with the test organisms such as gastrointestinal infection, respiratory problems, cold, fever, allergies, urinary tract infection, fungi infections, and arthritis [34]. Also, the marked antibacterial and antimycotic action exhibited by the extracts of Aframomum melegueta on the test organisms which are associated with spoilage of bread and tomatoes is an indication that this extract can be incorporated into food items as preservative to prolong the shelf life of food and food products.

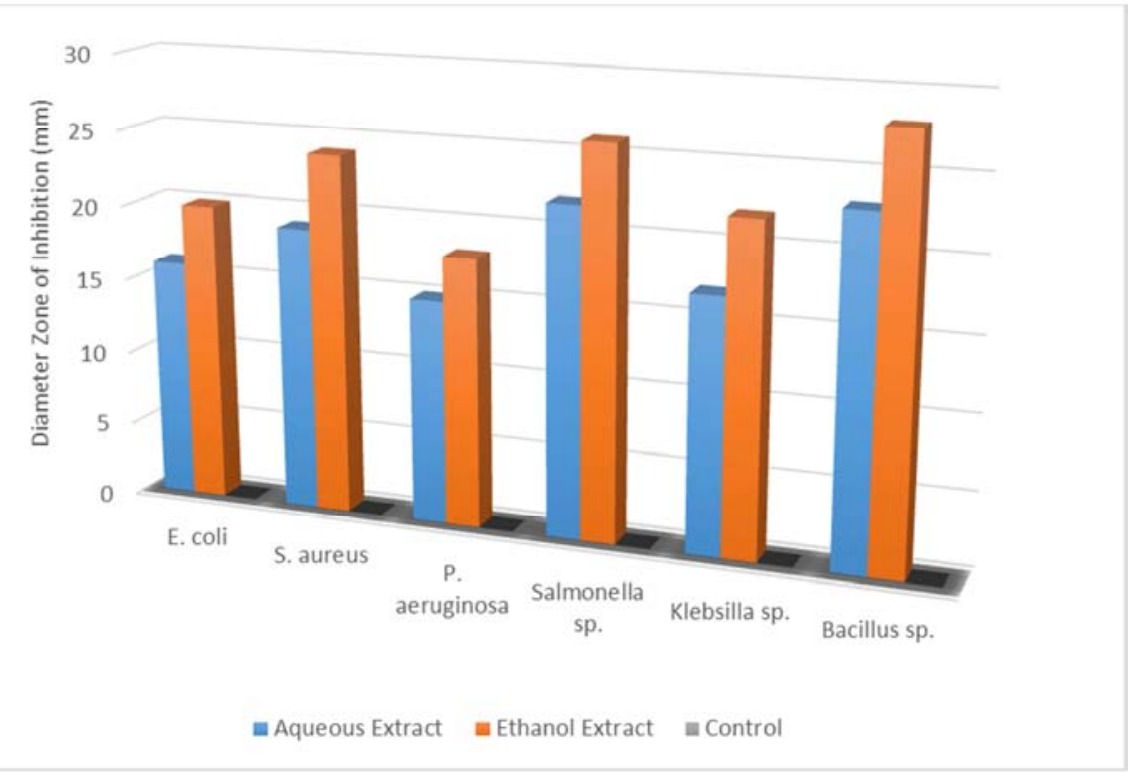

Figure 1. Antibacterial activity of seed extracts of Aframomum melegueta. Values are mean of triplicate determination.

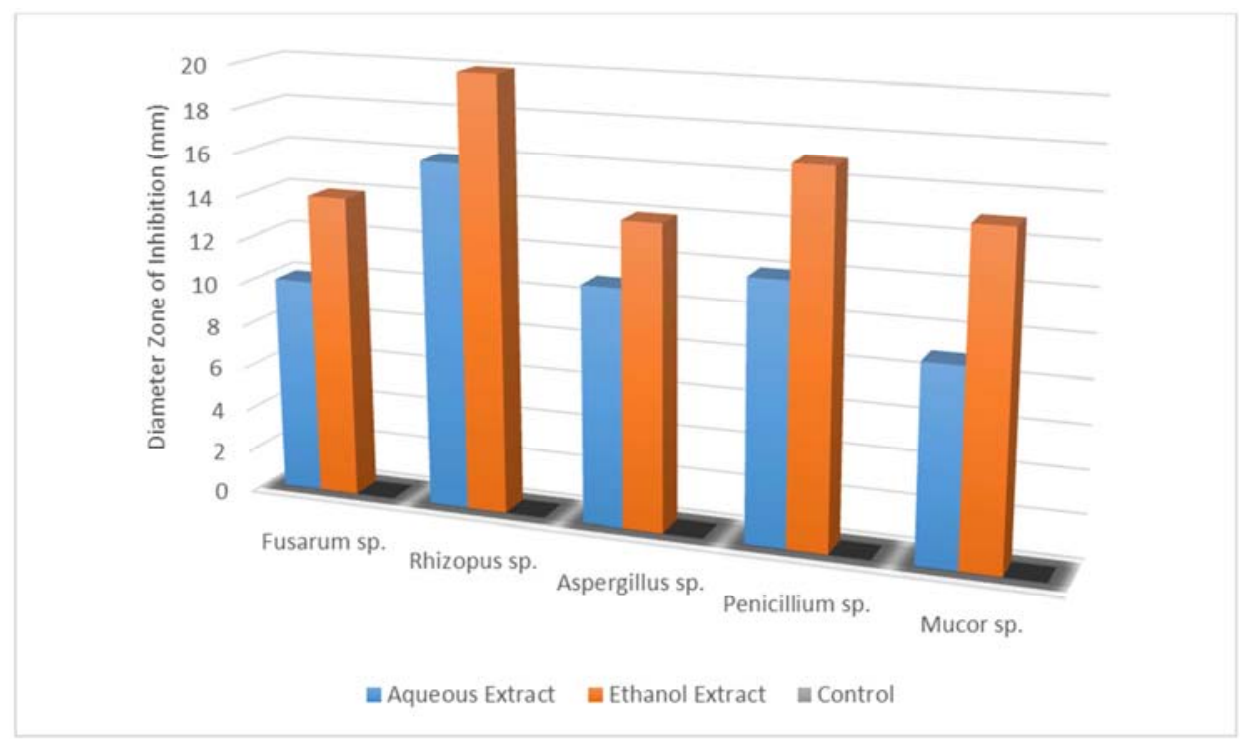

Figure 2. Antifungal activity of seed extracts of Aframomum melegueta. Values are mean of triplicate determination.

\subsection{Minimum Inhibitory Concentrations (MICs)}

Table 2 presented the minimum inhibitory concentrations (MICs) of the aqueous seed extracts of Aframomum melegueta on the test organisms. The result showed that the
MIC of E. coli, S. aureus, Salmonella sp. and Bacillus sp. was $20 \mathrm{mg} / \mathrm{mL}$. Also the MIC the MIC for P. earuginosa, Klesiella sp. and Rhizopus sp. was $30 \mathrm{mg} / \mathrm{mL}$ while Fusarium sp., Aspergillus sp., Penicillium sp. and Mucor sp. have MICs of $50 \mathrm{mg} / \mathrm{mL}$ respectively. 
Table 2. Minimum inhibitory concentration of the aqueous seed extract of Aframomum melegueta.

\begin{tabular}{llllll}
\hline \multicolumn{7}{l}{ Test organisms } & & & \\
\hline Concentration (mg/mL) & Escherichia coli & Staphylococcus aureus & Pseudomonas aeruginosa & Salmonella species & Klebsiella species \\
\hline 150 & - & - & - & - & - \\
100 & - & - & - & - & - \\
50 & - & - & - & - & - \\
30 & - & - & + & - & + \\
20 & + & + & + & + & + \\
10 & + & + & + & + & + \\
5 & + & + & + & + & + \\
\hline
\end{tabular}

- = absence of growth; $+=$ presence of growth

Table 2. Continue.

\begin{tabular}{|c|c|c|c|c|c|c|}
\hline & Test organisms & & & & & \\
\hline Concentration $(\mathrm{mg} / \mathrm{mL})$ & Bacillus species & Fusarium species & Rhizopus species & Aspergillus species & Penicillium species & Mucor species \\
\hline 150 & - & - & - & - & - & - \\
\hline 100 & - & - & - & - & - & - \\
\hline 50 & - & + & - & + & + & + \\
\hline 30 & - & + & + & + & + & + \\
\hline 20 & + & + & + & + & + & + \\
\hline 10 & + & + & + & + & + & + \\
\hline 5 & + & + & + & + & + & + \\
\hline
\end{tabular}

- = absence of growth; $+=$ presence of growth

The MICs of the ethanolic seed extracts of Aframomum melegueta showed that E. coli and $S$. aureus have MICs of $10 \mathrm{mg} / \mathrm{mL}$, P. earuginosa, Klesiella sp., Penicillium sp. and
Rhizopus sp. have $20 \mathrm{mg} / \mathrm{mL}$ respectively, Fusarium sp., Aspergillus sp. and Mucor sp. have $30 \mathrm{mg} / \mathrm{mL}$ while Bacillus sp. was the most susceptible with MIC of $5 \mathrm{mg} / \mathrm{mL}$ (Table 3).

Table 3. Minimum inhibitory concentration of the ethanolic seed extract of Aframomum melegueta.

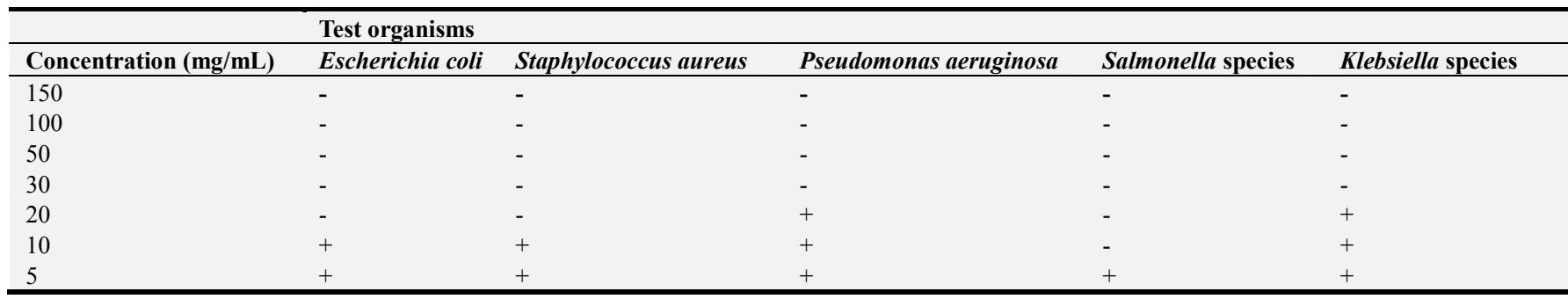

- = absence of growth; $+=$ presence of growth

Table 3. Continue.

\begin{tabular}{|c|c|c|c|c|c|c|}
\hline & Test organisms & & & & & \\
\hline Concentration (mg/mL) & Bacillus species & Fusarium species & Rhizopus species & Aspergillus species & Penicillium species & Mucor species \\
\hline 150 & - & - & - & - & - & - \\
\hline 100 & - & - & - & - & - & - \\
\hline 50 & - & - & - & - & - & - \\
\hline 30 & - & + & - & + & - & + \\
\hline 20 & - & + & + & + & + & + \\
\hline 10 & - & + & + & + & + & + \\
\hline
\end{tabular}

- = absence of growth; + = presence of growth

The minimum inhibitory concentration (MIC) assay of the plant extracts revealed that the MICs for both leave and stem bark were low ranging from $50 \mathrm{mg} / \mathrm{mL}$ to $5 \mathrm{mg} / \mathrm{mL}$. The observation also indicated that the ethanol extract of the seed of Aframomum melegueta was more effective at low concentrations than the aqueous extract. However, the bacteria are more susceptible to the extracts than fungi. This low MICs is an indication of strong antibacterial and antimycotic effect on the test organisms, particularly the ethanol extract. It also implies that the extracts are very effective at very low doses. Hence can be effective in combating infections by the bacteria and fungi tested and as well used in food preservation. 


\section{Conclusion}

The present study has shown that the seed extracts of Aframomum melegueta are effective against the selected food spoilage organisms. However, the ethanol extract exhibited a much better antibacterial and antifungal effect on the test isolates than the aqueous extracts. Also, the extract showed low minimum inhibitory concentration (MIC) on the test organisms. Therefore, the extracts of Aframomum melegueta could be used in treating bacteria and fungi infections associated the test organisms at low doses. More so, the study has shown that the extracts of Aframomum melegueta can be incorporated in food or food products as preservative.

\section{References}

[1] de-Souza, E. L., Stamford, T. L., Lima, E. D., Trajano, V. N. and Filho, J. M. (2005). Antimicrobial effectiveness of spices: approach for use in food. Brazilian Archives of Biology and Technology International Journal, 48: 549-558.

[2] Rios, J. L. and Recio, M. C. (2005). Medicinal plants and Antimicrobial activity. Journal of Enthopharmacology, 100: 80 .

[3] Doherty, V. F., Olaniran, O. O. and Kanife U. C. (2010). Antimicrobial Activities of Aframomum Melegueta (Alligator Pepper). International Journal of Biology, 2 (2): 126-131.

[4] Sofowora, A. (1993). Medicinal plants and Traditional Medicine in Africa. Spectrum Books Limited, Ibadan, Nigeria, p 346.

[5] Edeoga, H. O., Okwu, D. E. and Mbaeble, B. O. (2005). Phytochemical Constituents of some Nigerian Medicinal Plants. African Journal of Biotechnology, 4: 685-688.

[6] Galal, A. M. (1996). Antimicrobial activity of 6-paradol and related Compounds. International Journal of Pharmacognosy, 31: $37-43$.

[7] Ikegbunam, M., Maduagwu, U. and Osazuwa, E. (2016). Evaluation of the Antifungal Activity of Aqueous and Alcoholic Extracts of Six Spices. American Journal of Plant Sciences, 7: 118-125.

[8] Okwu, D. E. (2001). A improving Nutritive value of cassava Tapiocmeal with local spices. Journal of Nutraceutical, Functional and medical food, 3: 43-51.

[9] Okwu, D. E. (2004). Phytochemicals and vitamin content of Indigenous spices of South Eastern Nigeria. Journal of Sustain Agricultural environment, 6: 30-34.

[10] Oladunmoye, M. K. and Dada, E. O. (2007). Comparative studies on the Antimicrobial activity of leafs extracts from Aframomum melegueta. Research Journal of Botany, 2 (2): 95-107.

[11] Okigbo, R. N, Ogbonnanya, O. U. (2006). Antifungal effects of two tropical plants extracts Ocimum gratissimum and Afromaomum melegueta on post-harvest yam Discorea spp rot. African Journal of Biotechnology 5 (9): 727-731.

[12] Iwu, M. M. (1999). Handbood of African Medicinal plants. CRC Press, Boca Raton FL, pp 205-210.
[13] Indu, M. N., Hatha, A. A., Abinosh, C., Harsha, U. and Vivekanandan, G. (2006). Antimicrobial activity of some South Indian spices against serotypes of Escherichia coli, Samonella, Listeria monocytogenes and Aeromonas hydrophila. Brazilian Journal of Microbiology, 37: 153 - 158.

[14] Ray, B. (2004). Fundamental food microbiology, $3^{\text {rd }}$ edition. CRC Press, New York.

[15] WHO (2007). Foodborne Disease Outbreak Guidelines. www.who.int/foodsafety/publications/foodborne_disease/FER G_Nov07pdf. Date accessed, June 23, 2013.

[16] Ogodo A. C. and Ekeleme U. G. (2013). In-vitro antibacterial activity of garlic cloves and ginger rhizomes on food-borne pathogens. International Journal of Basic and Applied Sciences, 2 (4): 387-392

[17] Ogodo, A. C. and Ugbogu, O. C. (2016). Public Health significance of aflatoxin in food industry-a review. European Journal of Clinical and Biomedical Sciences, 2 (5): 51-58.

[18] Ronald, M. A. 1994. Principal of Microbiology. USA. 597 644.

[19] Okwu, D. E. and Njoku, E. E. (2009). Chemical composition and in-vitro antifungal screening of seed and leaf extracts from Afromaomum melegueta and Monodora myristica against rolfsii of cowpea plant (Vigna ungukulata L. Walp)

[20] Alo, M. N., Anyim, C., Igwe, J. C., Elom, M. and Uchenna, D. S. (2012). Antibacterial activity of water, ethanol and methanol extracts of Ocimum gratissimum, Vernonia amygdalina and Aframomum melegueta. Advances in Applied Science Research, 3 (2): 844-848.

[21] Ekeleme, U. G., Nwachukwu, N. C., Ogodo, A. C., Nnadi, C. J., Onuabuchi, I. A. and Osuocha, K. U. Phytochemical Screening and Antibacterial Activity of Cnidoscolus aconitifolius and Associated Changes in Liver Enzymes in Wistar Rats. Australian Journal of Basic and Applied Sciences, (12): 156-162

[22] Arekemase, O., Kayode, O. and Ajiboye, E. (2011). Antimicrobial Activity and phytochemical analysis of Jatropha curcas plant against some selected microorganisms. International Journal of Biology, 3 (3): 52-55.

[23] Amusa, N. A., Kehinde, I. A. and Ashaye, O. A. (2002). Biodeterioration of Bread fruit in storage and its effects on the Nutrient Composition. African Journal of Biotechnology, 1 (2): 57-60.

[24] Okereke, H. C. and Kanu, I. J. (2004). Identification and characterization of Microorganisms In: Laboratory guide for microbiology, A. Onyeagba, (ed). Crystal Publishers, Okigwe, pp. 95-110.

[25] Holt, J. G., Kieg N. R; Sneath, P. H. A; Staley, J. T. and Williams, S. T. 1994. Bergey s Manual of Determinative Bacteriology $\left(9^{\text {th }}\right.$ edition). The Williams and Wilkins Company Baltimore, U. S. A. Pp 787.

[26] Barnett, J. A., Payne, R. W., Yarrow, D. (2000). Yeasts characteristics and identification, $3^{\text {rd }}$ ed. Cambridge University Press. Cambridge.

[27] Oyeleke, S. B. and Manga, S. B. (2008). Essentials of Laboratory Practical in Microbiology. Tobest Publisher, Minna, Nigeria. Pp 36-75. 
[28] Doughari JH, Pukuma MS, De N. (2007). Antibacterial effects of Balanites aegyptiaca L. Drel. and Moringa oleifera Lam. on Salmonella typhi. African Journal of Biotechnology, 6(19): 2212-2215.

[29] Oyemaechi, U. F. Chukwuezi, O. and Ozougwu, V. E. O. (2014). Microbial Agents of Tomato Spoilage in Onitsha Metropolis. Advances in Biological Research 8 (2): 87-93.

[30] Mbajiuka, S. C. and Enya, E. (2014). Isolation of Microorganisms associated with Deterioration of Tomato (Lycopersicon esculentum) and Pawpaw (Carica papaya) Fruits, International Journal of Current Microbiology and Applied Science, 3 (5): 501-512.

[31] Unachukwu M. N. and Nwakanma, C. (2015). The fungi associated with the spoilage of bread in Enugu state. International Journal of Current Microbiology and Applied Sciences, 4 (1): 989-995.
[32] Ravimannan, N., Sevvel, P. and Saarutharshan, S. (2016). Study on fungi associated with spoilage of bread. International Journal of Advanced Research in Biological Sciences, 3 (4): 165-167.

[33] Oyagade, J. O., Awotoye, O. O., Adewunmi, J. T., and Thorpe, H. T., (1999) Antimicrobial activity of some Nigerian medicinal Plants, screening for antibacterial activity. Journal of Bioscience research Communication, 11: 193-197.

[34] Odetunde, S. K. Adekola, I. T. Avungbeto, M. O. and Lawal, A. K. (2015). Antimicrobial effect and phytochemical analysis of Aframomum melegueta on some selected bacteria and fungi. European Journal of Biotechnology and Bioscience, 3 (4): $15-19$. 